\title{
BELAJAR MEMAHAMI TURATS
}

\section{Oleh Wildana Wargadinata*}

\section{Penulis adalah Dosen Muda STAIN Malang dan Sekretaris PKPBA STAIN Malang}

\section{Pendahuluan}

Saat mendengar kata-kata turats yang terbayang pada diri kita adalah tumpukan buku yang menggunung. Sebuah gunung yang nampak besar dari jauh dan angker. Mengundang tanda tanya dan menyimpan seribu rahasia. Hal ini memang sangat beralasan, karena kitab-kitab turats adalah hasil kerja keras ulama salaf yang tidak hanya dalam waktu satu dua tahun saja melainkan hasil kerja beratus-ratus tahun. Semakin kita telusuri semakin kita dapati bahwa di depan kita adalah hasil buah pemikiran otak-otak cemerlang yang mencengangkan. Besar dari segi massanya (sepuluh abad), besar dari segi tempatnya (karena dia berasal dari Andalus ke India dan dari sebelah utara Afrika ke bagian selatan), besar juga dari segi variasinya karena dia meliputi ilmu-ilmu eksak clan non-eksak juga dari alirannya dan madzhab-madzhabnya.

Turats juga mengundang sekian pertanyaan karena perbedaan/gap generasi yang sangat panjang. Generasi sekarang telah kehilangan syafrab-syafrab (rumusan yang dulu sangat populer di kalangan Salaf Saleh). Tulisan ini adalah sebuah pengantar dalam usaha mengembalikan lagi hubungan yang sempat putus antara generasi sekarang dengangenerasi Salaf Saleh agar kita ticlak terputus clengan masa lampau dan agar kita benar-benar dapat mewarisi warisanwarisan orang-orang dulu yang sangat kaya dengan kecemerlangan.

\section{DefinisiTurats}

- Turats menurut Dr. Ali Jum'ah adalah hasil buah pemikiran ulama salaf sejak masa pembukuan ('asbrut tadwin) akhir abad pertama hijrah sampai seratus tahun sebelum masa kita sekarang ini, atau tepatnya buku terakhir yang ditulis dengan gaya turats adalah buku "Al Burhan lil Bajuri" yang meninggal pada tahun 1959."

Sebetulnya istilah turats belum dipakai sebagaimana yang kita pahami sekarang bahkan pada masanya Rifaah Thahthawi Muhammad Abduh dan Ahmad Zaki Basya, (Syaikbul 'Unubbab). ") Pada saat mereka memulai proyek menghiclupkan kembali turats istilah yang mereka pakai adalah ibyaul kutub. Istilah turats pertama kali dipakai oleh AlUstadz Ahmad Amin yang diikuti oleh Syeikh Kausari hanya saja istilah itu terbatas pada bidang fiqih dan fuqaha. Istilah turats mulai banyak dipakai di bidang sastra mulai tahun 50-an clan akhir 40-an.

Massa Khedu Ismail adalah masa pemisah antara zaman turats dan pasca turats, maksudnya zaman khedu Ismail aclalah zaman dimana fase turats telah berakhir, ini terlihat dengan jelas terutama dari cara berpikir clan gaya hidup. Para Salaf Saleh menjadikan nash sebagai pilar kehidupan (way of life), menjadikan nash sebagai tonggak kebudayaan. Mereka benar-benar merespon agama dan mengimplementasikan dalam kehidupan keseharian mereka : tidur setelah isya bangun sebelum fajar, mereka benar-benar memahami kata "ssulutssul lail". 
Segala aktivitas hidup mereka benar-benar mengikuti nash, mereka menjadikan dirinya buruh nash (Khadim al-Nash) Sehingga muncullah ilmu-ilmu yang hakekatnya untuk menghidupkan nash seperti Nahwwu, Sharf, Balaghah, Fiqh, Ushul, Ilmu Kalam, Aswat dll. Wa kaannaka ra'ayta annasa yadkbulluna fi dinillabi afwaja."(Dan seolab-olab kamu menyaksikan umat manusia berbobdongbondong memasuki Agama Allab)".

Sebaliknya ciri dari fase pasca turats, keterikatan mereka terhadap nash atau agama mulai berkurang bahkan hilang. Sebagai contoh di negara yang mayoritas Muslim seperti Mesir trend menonton opera bahkan menyalahi waktuwaktu syari'at, mereka berangkait sebelum maghrib keluar tengah malam dan bangun kesiangan, hilang shalat maghrib, hilang tsulutsul lail hilang fajar. Sementara sopir-sopir taksi menunggu penumpangnyal mengalami hal yang sama menghilangkan waktu-wwaktu yang berharga bagi mereka. Itu satu contoh kasus, kasus yang lain sangat banyak, pertunjukan konser, sepak bola, bioskop dan lain-lain. Wa ka annaka ra'ayta annasa yakbrujuna min

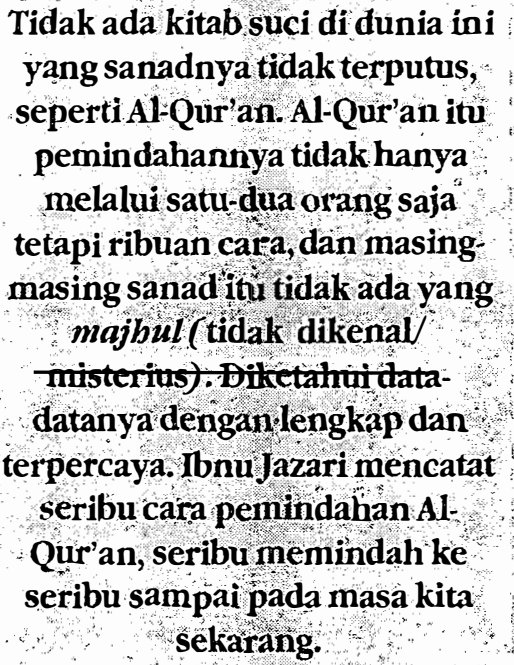

mewujudkan apa yang menjadi bahan pikiran mereka.

Tidak ada kitab suci di dunia ini yang sanadnya tidak terputus, seperti Al-Qur'an. Al-Qur'an itu pemindahannya tidak hanya melalui satu-dua orang saja tetapi ribuan cara, dan masing-masing sanad itu tidak ada yang majbul (tidak dikenal/misterius). Diketahui data-datanya dengan lengkap dan terpercaya. Ibnu Jazari mencatat seribu cara pemindahan Al-Qur'an, seribu memindah ke seribu sampai pada masa kita sekarang. Sebelum perang dunia ke clua didirikan Institut Perbandingan teksteks Kitab Suci di Jerman. Salah satu sebab didirikannya Institut tersebut karena orang-orang Barat sudah bosan atas kebanggaan umat Islam terhadap kitab sucinya. Namun sebaliknya pusat kajian Jerman tersebut justru mendapatkan kenyataan bahowa Taurat itu hanya mempunyai dua orang sanad saja. Sanad terakhir clengan sumber aslinya itu bahkan berjarak seribu tahun. Sementara injil lebih mengenaskan lagi karena tidak mempunyai teks yaing asli, dan teks-teks yang tidak aslipun sanadnya adla yang kriminil, ada dinillabi afwaja (Dan seolab-olab kamu menyaksikan umat manusia berbondong-bondong keluar dari agama Allab).

\section{Otentikasi Sumber (Tautsiqul Mashdar)}

Masallah tsautsiq (penelusuran keaslian sumber) aclalah permasalah pertama yang clipertanyakan seorang manusia yang mencari kebenalran. "Apakah apa yang adla pada diri kita (Qur'an dan Sunnah) ini benar-benar dari Rasul?" adalah sebuah pertanyaan otentikasi sumber. Untuk menjawab pertanyalan seperti ini, telah tumbuh $20 \mathrm{ilmu}$, yang berhubungan dengan ilmu Rijal, ilmu Asanid, ilmu Jarh ra Ta'clil, ilmu Musthalah Hadits dlll. Semuanya berusaha untuk yang pembunuh, dan sekian kejelekan yang lain. Ini aclalah hasil penelitian mereka.

Hal ini merupakan musibah bagi peradaban ada umat manusia yang masih dibingungkan oleh keaslian pegangan hidupnya. Sebaliknya AlQur'andengan tegas clan jelas dijamin akan dijaga Allah sampai akhir zaman. Dan diciptakan untuk mengalahkan setiap kitab suci yang adla di dunia ini dan sudah jelas ummat Islam telah membuktikan betapa kitab sucinya benar-benar outhentik dan sampai kepada sumbernya.

Sebut saja sebualh contoh bagaimana berhatihatinya para perawi nash dala m menjaga manusia. Pada era modern seperti sekarang ini, masih 
keautentikan nashnya. Imam Bukhari bahkan melakukain perjalanan yang sangat panjang untuk menemui perawi hadits. Suatu saat beliau bertemu dengan seorang yang dicarinya, saat itu memegang segenggam rumput memanggil kudanya atau dombanya, begitu sampai rumput itu dibuangnya dan dia pegang kudanya, apa kata Imam Bukhari "kamu melakukan itu dan kamu telah berbohong". Sampai sedemikian rupa riwayat seseorang diterima atau ditolak, orang itu dianggap sudah tidak terhormat, Nabi dulu juga berbuat yang sama, ketika seorang wanita mengimingkan korma untuk menangkap anak kecilnya, begitu mendekat kemudian dia membuang kormanya, Rasul berkata: "Apa yang telah kamu lakukan itu adalah perbuatan bohong".

Metode tautsiq ini yaitu metode yang berusaha menelusuri keaslian sumber mempengaruhi penulisan bukubuku yang lain pada masa ulama Salaf Shaleb hingga muncul ilmu Asbab wa al-Asanid, yang intinya membahas otentikasi sumber. Akhirnya saat merekal membaca buku, mereka harus yakin benar bahwa buku ini dikarang oleh pengarangnya.

Tradisi otentikasi sumber ini betul-betul telah mendarah daging dari hanya sebuah metode menjadi sebuah malakab pada diriumat Islam. Hal inilah yang mengungkap/membocorkan berbagai usăha penyelewengan danusaha pengaburan dari pihak-pihak yang membenciturats Islam.
Maka mencari keotentikan (keaslian) sumber adalah masalah yang sangat penting.

Ibnu Shalah dalam pendahuluan bukunya menerangkan bagaimana menulis teks-teks dan cara pemindahannya. Dan bagaimana kita memelihara kebenarannya; "Ketika saya membaca sebuah teks, kemudian saya dapatkan kesalahan atau kekurangannya, saya tidak langsung membetulkannya tetapi saya hanya memberi tanda kemudian saya keluar dari halaman teks (di pinggiran halaman) dan saya terangkan apa yang menjadi keyakinan saya dan apa-apa yang saya dapat dari buku lain. Hal ini saya lakukan agar generasi yang akan datang mendapatkan teks yang asli yang belum berubah dan memberi kesempatan kepada mereka untuk menilainya. Boleh jadi apa yang saya anggap salah ternyata malah betul dan sebenarnya".

Tradisi otentikasi sumber ini betul-betul telah mendarah daging dari hanya sebuah metode menjadi sebuah malakab pada diri umat Islam. Hal inilah yang mengungkap/membocorkan berbagai usaha penyelewengan dan usaha pengaburan dari pihakpihak yang membenci turats Islam.

Kita sekarang sudah kehilangan metode otentifikasi salaf yang telah mendapat ilmu yang manakah yang berbentuk bangunan. Kita tidak lagi memiliki ilmu tetapi hanya kepingan-kepingan ilmu atau pengetahuan saja. Perbeclaan antara ilmu dan pengetabuan adalah bahwa pengetahuan itu bagian atau kepingan-kepingan ilmu sedang ilmu adalah bangunan yang utuh yang berhubungan antara satu dengan yang lain, memiliki metode dan kegunaan. Dari sini kita dapat juga membedakan antara ilmuwan dan budayawan. Budayawan adalah orang yang memiliki pengetahuan pada materi-materi tertentu tetapi ticlak mengerti pengtahuan itu. Maka kita harus tahu metocle sebuah ilmu menyadari cara penggunaannya, tahu hubungan antara bagianbagian ilmu tersebut dan kita menyadari ilmu itu sendiri shingga kita benar-benar clapat memperoleh bangunan ilmu yang utuh.

Ada clelapan cara perolehan ilmu (Thuruqu tabammulil 'ilm) yang mereka ambil dari para ahli hadits"), yang diringkas menjadi tiga hal :

Pertama As Sima', yaitu seorang syaikh membaca dan muridnya mendengar ini adalah cara yang paling terpercaya. Yang kedua Qira'ab 'ala As Syaikb atau Al 'Ardl ini tingkatannya dibawah yang pertama. Yang terakhir adalah $A l$ Wijadab artinya kita hanya mendapat sebuah tulisan tanpa di tathbiq 
sebagaimana yang kita lakukan pada saat membaca sebuah buku.

Ala kulli hal kebudayaan umat Islam belum mati, hanya tidur saja sebuah tidur yang angat panjang dan orang yang tidur suatu saat akan bangun Wallabu Yab'atsu man fil Qubur. Masa tidur panjang ini dimulai dengan masuknya teks dan manuskripmanuskrip ilmu ke percetakan. Percetakan pertama yang berdiri adalah Percetakan Amiriyyab yang berdiri pada tahun 1800-an percetakan ini mulai menciptakan hasil karya. Tiga puluh tahun kemudian bar mencetak Al qur'an. Keterlambatan pencetakan Al Qur'an ini karena adanya protes dari kaum ulama disebabkan oleh dua hal :

1. Mereka takut terjadi banyak kesalahan, mereka lebih percaya kalau ditulis dengan tangan karena hal itu lebih menjamin kehati-hatiannya.

2. Mereka mendengar salah satu onderdil percetakan terbuat dari kulit babi. Mereka tidak rela kitab sucinya dicemari oleh barang haram.

Protes ulama ini tidak berjalan panjang karena Muhammad Ali Basya kemudian memerintahkan dengan tegas percetakan Al Qur'an meski dengan cara yang haram. Ini adalah salah satu kasus dimulainya keterputusan urusan politik dengan agama.

Ada hal menarik dari percetakan Amiriyyah, para editor naskahnya adalah ulama-ulama yang paling besar tidak seperti zaman sekarang yang editornya tidak tahu dan tidak mengerti apa yang harus diperbuat Editor zaman dulu benar-benar ahli dalam bidangnya menjadi rujukan masyarakat dalam bidangnya, sebagai contoh adalah syaikh Quththal Adawy, syaikh Nasr Huriry, seorang syaikh yang menulis pengantar Dibajab (pendahuluan) atas kamus Al Muhith wal Wasith. Perlu diketahui yang mengarang pengantar ini tidak ada lain kecuali dia harus lebil pandai dari Fairuz Abadi. Dari sini terlihat betapa editor naskah percetakan zaman dahulu adalah bukan orang sembarangan. Demikian juga dengan Hasan Bik, Ahmad Zaki Basya, Alımad Basya Taimur dan lain sebagainya.
Turats saat itu mendapatkan perhatian yang sangat besar dari pada ulama dan percetakan Amiriyyah sampai sekarang menjadi pioner (Umdab) percetakan yang terpercaya. Masalah otentikasi sumber benar-benar mereka jalankan pada saat proses pengalihan manuskrip ke percetakan.

\section{Penulisan Turats Gaya Baru}

Penulisan turats dengan cara baru dimulai oleh para orientalis yang kemudian diikuti oleh DR. Abdussalam Harumi dan DR. Ahmad Syalaby. Penulisan-ini memiliki ciri-ciri yang khas yang intinya tidak lagi terikat dengan bentuk akan tetapi lebih ditekankan kepada pemahaman isi. Makanya tulisan ini dilengkapi dengan daftar isi (fibris), catatan kaki, keterangan kosakata dan lain-lain yang saat ini kita kenal dengan buku-buku mubagqaqatau buku yang sudah ditabqiq.

\section{Memamahi Syafratut Turats}

Banyak orang yang menolak keras turats tanpa alasan yang jelas, dikarenakan mereka belum memahaminya.. Sebaliknya banyak juga yang menerima turats dengan bulat tetapi juga memahaminya. Yang ini mungkin lebih baik dari yang pertama karena masil mengikuti tradisi salaf shalih. Ketidakpahaman mereka terhadap turats, karena mereka telah kehilangan rumusan yang dimiliki para salaf yang mereka pakai dalam setiap tulisannya. Setiap turats ditulis dengan syafrab (kode), syafrab itu sendiri maksudnya adalah sebuah rumusan tertentu yang dipakai oleh sekelompok manusia untuk mengadakan hubungan rahasia antara mereka. Syafratut turats disini bukan berarti rahasia yang harus disimpan akan tetapi memang telah dipakai diantara ulama salaf. Maka untuk memahaminya kita harus memahami Syafratut turats para salaf. Ada lima syafrab yang akan kita singgung disini mewakili syafrab-syafrab yang lain :

\section{Tashawwurat Kulliyah}

Para Salah Saleh memiliki tasbawwurat kulliyab yang tersebar di berbagai buku, diantaranya akan 
kita dapati pada pembukaan ilmu kalam, mantiq shuri atau pada ilmu yang tidak kita pelajari lagi yaitu $A l$ Hikmah Al 'Aliyah. Pembahasan dalam tashawwurat kulliyab berkisar pada al wujud dan adam, sebetulnya saat kita merenungi ilmu-ilmu turats kita juga akan dapat mengambil dan memahaminya.

Ada beberapa ulama salaf yang berusaha menerangkan safrab ini dengan cara yang lain diantaranya Ibnu Badran dalam bukunya "Madkbal". Demikian juga para penguasa Turki yang begitu interes menggali dan mencoba memahami turats.

Permasalahan pertama dari tashawwur Kulli adalah al wujud. Wujud dibagi dua :

1. Jaubar yaitu ma labu bayyizun

2. 'Ardl yaitu ma laisa labu bayyizun.

Pemikiran ini dipakai diberbagai ilmu turats seperti dalam Fiqh, Ushul fiqh, Nahwu, Sharf dan lain-lain. Banyak cara untuk menjaga tashawwurat kulliyab diantaranya memakai nadbm yang dinyạnyikan, yang dalam istilah tajwid disebut tuhfatul Athfal seperti, al maqulat al-Ashru (masalah Jauhar Al'Ardh)

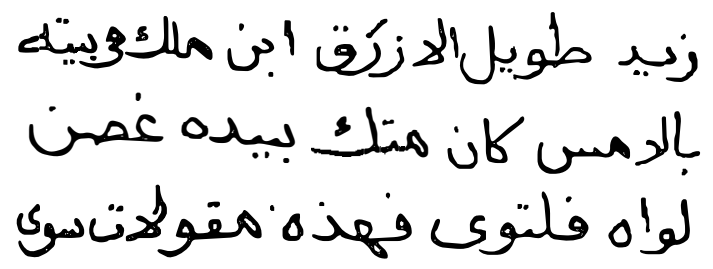

Nadham diatas mengumpulkan teori-teori jauhar dan 'Ardb yang terdiri dari : 1. Jaubar, 2. Kam, 3. Kaif, 4. Nisbah, 5.Makan, 6. Zaman, 7. Wadh', 8. Milk, 9. Fi'lun, 10. Infi'alun. Selain itu juga tashawun' tentang taqsimul 'ilmi, ishawuurul Idrak kepada yakin, syak, dhann dan lain-lain (untuk lebih jelasnya baca "al mursyidussalim fil Mantiq badits wal qadim" karangan Dr. "Iwadullah Jad Hijazy, mantan Rektor Azhar, Muqarrar tingkat dua fakultas Studi Islam".i)

\section{Nadhariyyatul Hakimah (teori-teori yangsudah mapan)}

Sebuah teori-teori yang telah dimiliki dan tersebar diberbagai ilmu. Contohnya dalam Nahwu, a. Nadhariyyatul Mabal : bahwa dalam sebuah kalimat itu ada mustatbil, antara mustatbil yang satu dengan yang lain terdapat maball.

b. Nadhariyyatul Amal : Yaitu tentang kata-kata yang memiliki pengaruh terhadap kata-kata yang lain

c. Nadhariyyatul Nisbab: Tentang hubungan antara Al Maball dengan yang lain.

Dari teori-teori diatas kita bisa memahami "al jumlab allati laisa labu maballun fil 'Irab (kalimat yang tidak memiliki jabatan dalam l'rab). dan sebagainya.

\section{Al Musthalahat wa Ta'rifat (Istilah-istilah dan definisi)}

a. Dalam peristilahan kata terdapat perbedaan antara:

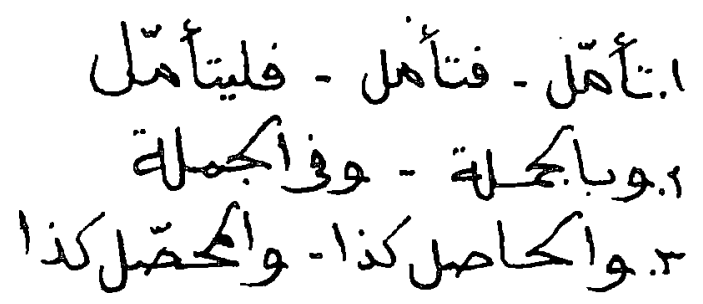

b. Dalam peristilahan Syakbsiyab terdapat perbedaan:

1. Al-qodli : Dalam Tafsir adalah Baidhawi, dalam Ilmu kalam adalah Abu Bakar Al Bakelani

2. Al-Imam : Dalam fiqih adalah Juwaini, dalam Ushul adalah Fakhrur Razi

3. Asy Syaikb: Asy-syaikhani dalam fiqih Syafi'i adalah Ar-rafi'i dan Nawawi sedang dalam Hadits adalah Buchari dan Muslim.

c. Dalam peristilahan Al qaul terdapat perbedaan antara :

1. AdbHar

2. Muqabilul Adh Har

3. Al Masyhur

4. Muqabilul Mashbur

5. Dha'if

6. Al Ashah 
7. Muqabilush Shahih

8. Dan lain-lain

\section{Al Ulum al Khadimah (ilmu-ilmu bantu)}

Yaitu sebuah ilmu yang bukan berupa spesialisasi tetapi ilmu yang digunakan untuk membantu memahami ilmu-ilmu yang lain seperti :

1. Ilmu mantiq yang melindungi manusia dari cara berpikir yang salah. Ilmu ini dipakai dalam ilmuilmu yang lain seperti ilmu kalam, fikih dan lainlain.

2. Ilmu Nabuu yang menghindarkan manusia dari kesalahan memakai kata-kata. Ilmu ini juga terpakai calam ilmu-ilmu lain seperti tafsir, fiqih, Hadits dan lain-lain.

\section{Shiyaghah al mantiqiyah wal lughawiyyah}

Ini ạdalah syafrah terakhir yang kita pelajari dalam rangka membantu memahami kitab turats.Syiyaghal al-Mantiqiyah dan lughawiyyah adalah jenis-jenis kata dalam ilmu mantiq dan ilmu bahasa. Istilah tersebut akan sangat asing bagi yang orang yang tidak mempelajari ilmu mantiq (logika) dan ilmu-ilmu bahasa (nahwu, shorof, balaghoh). Syiyaghoh ini pada masa sekarang dikenal dengan istilah idiom.

\section{Penutup}

Turats bagaimanapun tetap masih berupa tekateki bagi kita, apa yang penulis sampaikan diatas hanya setitik dari usaha memahami turats. Turats masih terlalu besar untuk kita pahami dan kita mengerti delik-delik isinya. Semoga tulisan ini mengantarkan kita kepada kesadaran betapa turats yang kita miliki sekarang ini memiliki nilai yang begitu cemerlang yang harus kita gali lebih dalam lagi. Dig little more.

\section{CATATAN KAKI :}

1. Ceramah Unum, Dr. Ali Jum'ah tentang usaha memahami turats, Januari 1995 di Dokki (Ceramah tersebut adalah sumber utama tulisan diatas)

2. Rif'at Thantawi memulai proyek menghiclupkan kembali turats saat beliau kembali dari Paris tahun 1881. Muhammad Abduh mulai berbicara tentang turats sejak awal 1880-an dan mulai menulis bukunya "Badiu zaaman al hamzani" saat beliau di Libanon tahun 1886. Selanjutnya usaha tersebut dilanjutkan oleh Ahmad Zaki Basa, Syaikhul Auruba. Lihat seminar "Kaifa Nata'amal Ma'a Turats" oleh Dr. Muhammad Imarah, Ma'ha Al fikir Al Islami, 1990.

3. Untuk lebih jelasnya lihat "Qawa"id Ushulul Hadits" Dr. Umar Hasyim, Muqarrar tingkat satu, Studi Islam.

4. Al-Mursbidu assalim fil Mantiqil Hadits wal Qadim, Dr. 'Iwadullah Jad Hijazi, Muqarrar tingkat dua, Studi Islam.

\section{DAFTAR PUSTAKA}

1. Dr. Husain Muhammad Sulaiman, al-Turats alAraby al-Islamy, Kairo : Dar al-Sya'b, 1987

2. Dr. Muhammad Abid al-Jabiri, al-Turats wa alHadasab, Beirut : al-Markaz al-Tsaqafi al-Araby, Cet.I, 1991

3. Syaikh Muhammad al-Ghazali, Turatsuna alFikn, Herndon : The International Institute of Islamic Thought, Cet. III, 1993.

4. Dr. Ali Omalil, al-Khitob al-Tarikby, al-Dar alBaidha' : al-Markaz al-Tsaqafi al-Arabi, Cet. III, 1985

5. Muhammad Qutub, Kaifa Naktub al-Tarikb alIslamy, Kairo : Dar al-Syuruq, Cet. I, 1992 